\title{
Myosin molecule packing within the vertebrate skeletal muscle thick filaments. A complete bipolar model ${ }^{\star}$
}

\author{
Ludmila Skubiszak ${ }^{\bowtie}$ and Leszek Kowalczyk
}

Laboratory of Computer Simulation of Muscle Contraction, Institute of Biocybernetics and Biomedical Engineering of the Polish Academy of Sciences,

Ks. Trojdena 4, 02-109 Warszawa, Poland

Received: 03 October, 2002; revised: 21 October, 2002; accepted: 13 November, 2002

Key words: thick filament, myosin molecule packing, cross-bridge action, vertebrate skeletal muscle, computer modelling

\begin{abstract}
Computer modelling related to the real dimensions of both the whole filament and the myosin molecule subfragments has revealed two alternative modes for myosin molecule packing which lead to the head disposition similar to that observed by EM on the surface of the cross-bridge zone of the relaxed vertebrate skeletal muscle thick filaments. One of the modes has been known for three decades and is usually incorporated into the so-called three-stranded model. The new mode differs from the former one in two aspects: (1) myosin heads are grouped into asymmetrical cross-bridge crowns instead of symmetrical ones; (2) not the whole myosin tail, but only a 43-nm C-terminus of each of them is straightened and near-parallel to the filament axis, the rest of the tail is twisted. Concurrent exploration of these alternative modes has revealed their influence on the filament features. The parameter values for the filament models as well as for the building units depicting the myosin molecule subfragments are verified by experimental data found in the literature. On the basis of the new mode for myosin molecule packing a complete bipolar structure of the thick filament is created.
\end{abstract}

The features of vertebrate skeletal muscles are generally interpreted on the ground of the so-called three-stranded model of the thick filament. According to this model (for a review see: Squire, 1997), the myosin tails, arranged nearly parallel to the filament axis, contribute to the filament backbone and all the myosin heads are grouped on the filament surface

\footnotetext{
${ }^{\star}$ Preliminary results were presented at the 45th Annual Meeting of the Biophysical Society (Boston, 2001) and the results included in this paper at the 38th Meeting of the Polish Biochemical Society (Wrocław, 2002).

${ }^{凶}$ Corresponding author: Ludmila Skubiszak, tel.: (48 22) 6599143 ext. 208; fax: (48 22) 659 7030; e-mail: Ludmila.Skubiszak@ibib.waw.pl
}

Abbreviations: CB, complete bipolar; LMM, light meromyosin; S2, myosin subfragment-2; TS, three-stranded. 
into symmetrical cross-bridge crowns. The tail arrangement suggests an oar-like action of the myosin cross-bridges, i.e. by bending of the myosin molecule in the so-called hinge domains: between $\mathrm{S} 2$ and LMM, between $\mathrm{S} 2$ and each myosin head, and within each head, in the so-called converter domain (for a review see: Huxley, 1980; Geeves \& Holmes, 1999). The symmetrical configuration of the cross-bridge crowns means that at each 14.3-nm level, three tail fragments, each ended with a pair of myosin heads, protrude from the filament backbone at the angles $0^{\circ}$, $120^{\circ}$, and $240^{\circ}$. Such a mechanism seems to be attractive, however, it is insufficient to explain all known phenomena (for a review see: Skubiszak, 1996a; Skubiszak \& Kowalczyk, 2001). That relates first of all to the muscle viscoelasticity, to the muscle ability for generation not only of axial, but also radial force, and to the high stereospecificity of the actin-myosin interaction.

The main techniques usually applied in muscle ultrastructural research are advanced light microscopy, electron microscopy (EM), and optical or X-ray diffraction (for a review see: Huxley, 1980; Squire, 1981). In electron micrographs, the thick filaments of vertebrate skeletal muscles so far examined (Sjöström \& Squire, 1977; Ip \& Heuser, 1983; Kensler \& Stewart, 1983; Cantino \& Squire, 1986; Kensler \& Stewart, 1986; Stewart \& Kensler, 1986; Kensler et al., 1994; Kensler \& Woodhead, 1995; Levine, 1997; Cantino et al., 2002; Eakins et al., 2002) appears as a bipolar rope with prominent, right-handed helical stripes uniformly extending across both arms of the filament with axial interval of about 43 $\mathrm{nm}$. Along each helical stripe there are 4 or 5 well-marked clusters axially about $14.3 \mathrm{~nm}$ apart. In the patterns depicting mass distribution within the filaments (Cantino \& Squire, 1986; Kensler \& Woodhead, 1995; Cantino et al., 2000) the transverse striping is much more prominent than the helical one. These stripes are grouped in sets of three; the sets and separate stripes are, respectively, $43 \mathrm{~nm}$ and $14.3 \mathrm{~nm}$ apart. During muscle contraction, the stripes on the filament surface disappear and the cross-bridges, protruding from the thick filament backbone towards the six surrounding thin filaments, appear. The cross-bridges form only in the zones of the stripes; so, the central zone, devoid of the cross-bridges, is usually called the bare zone. In the two polar halves, the helical stripes are identically inclined to the normal to the filament axis, at about $68^{\circ}$, but the protruding cross-bridges are oppositely tilted in relation to the filament axis. Both filament ends of about 43-nm length are sharpened. In a transverse view, the filament appears as a tube with the central diameter of $2-5 \mathrm{~nm}$ and a compact, relatively thick wall (Allakhverdov et al., 1981; Yu et al., 1985; Yu \& Brenner, 1986). Distribution of mass in the tube wall is regular, without any visible clusters. Passing the vertebrate skeletal muscle from resting into rigor state causes a shift of mass from the thick filament surface without any change in the appearance of a 14-22-nm thick backbone (Yu et al., 1985; Yu \& Brenner, 1986).

The forgoing experimental data show that the thick filament structure is quite complex and should not be described as a threestranded rope. The data reveal four shells specific for the filament: a thin central cylinder not consisting of myosin, a quite massive core (backbone) looking as a tube of stable structure, and two movable coats, one consisting of the tail fragments and the other, outer, of the heads. Previously (Skubiszak, 1990; Skubiszak, 1992; Skubiszak, 1993; Skubiszak, 1996a) we have shown that only a twisted arrangement of the myosin tails could explain the tube-like structure of the thick filaments. The idea of twisted tails seems to be accepted by Squire and co-workers (1997); however, Chew \& Squire (1995) suggested a very weak degree of twisting, i.e. such that leads to a near-parallel alignment of the myosin tails.

To elucidate the three-dimensional organization of the thick filaments usually reconstruction methods are used (Stewart \& Kensler, 
1986; Eakins et al., 2002). However, the reconstructions have been based on EM images of separate thick filaments the resolution of which is too low to define unambiguously the localization of each myosin head, to say nothing of the arrangement of the myosin tails. Thereby, the three-dimensional models based on such an approach show only a segment of the cross-bridge zone depicting the pairs of heads arranged on the surface of a cylinder. Another disadvantage of the conventional reconstruction method is that the $9 / 3$ helical symmetry of the filament has been introduced a priori.

We decided to use another approach, computer simulation. For this, we have devised a computer program (Skubiszak \& Kowalczyk, 1998) that allows creation of a complete filament structure from separate units representing the myosin molecule subfragments in a scale related to the real dimensions. On such ground we have analysed (Skubiszak, 1996b) different configurations of the cross-bridge crowns. As the crown configuration we mean both the alignment of the three cross-bridges in a crown and the mutual rotation between two successive crowns. From ten reasonable cross-bridge crown configurations we have selected three that could lead to the arrangement of all myosin heads on the filament surface sufficiently similar to that observed in EM images of the relaxed thick filament. One of the three cross-bridge configurations is that proposed three decades ago (Squire, 1972; Squire, 1973) and still prevailing (Squire, 1997; Eakins et al., 2002). According to it, each cross-bridge crown is symmetrical, i.e. the three cross-bridges are oriented at $120^{\circ}$, and rotation between successive crowns is $40^{\circ}$. In the two other configurations, the three cross-bridges are aligned either at the angles $0^{\circ}, 120^{\circ}$, and $180^{\circ}$ or $0^{\circ}, 180^{\circ}$, and $240^{\circ}$, i.e. each cross-bridge crown is asymmetrical, and rotation of the crowns is $240^{\circ}$.

Here we present two models based on the two alternative modes of myosin molecule packing. The models are named CB (the complete, bipolar model) and TS (the threestranded model). In the CB model we have introduced one of the two previously selected asymmetrical configurations of the crossbridge crowns and a new helical path for the arrangement of the myosin tails. In the TS model, the concept of symmetrical crossbridge crowns and near-parallel myosin tails, propagated by Squire and co-workers for a long time (Squire, 1973; Chew \& Squire, 1995; Hudson et al., 1997; Squire, 1997; Eakins et al., 2002), is incorporated. The concurrent presentation of the two alternative models might be helpful in elucidation of the advantages of the mode for the myosin molecule packing introduced by us.

\section{METHODS}

\section{Computation of the myosin filament struc- ture}

Both the CB model and the TS model are created from individual units corresponding to three specific subfragments of the myosin molecule (Cohen \& Holmes, 1963; Lowey et al., 1969; Burke \& Harrington, 1972; Elliott \& Offer, 1978; Stewart \& Edwards, 1984): light meromyosin (LMM), subfragment-2 (S2), and subfragment-1 (head) to a scale of all dimensions (Fig. 1). By independent arrangement of the subfragments, two hinge domains responsible for the myosin tail flexibility in the head-tail and S2-LMM junctions (Elliott \& Offer, 1978; Offer, 1990) are set into the filament models.

The filament backbone is built from the LMM units, each arranged along a helical path (Eqn. 1). Each S2 unit wraps the backbone along another helical path (Eqn. 2). All parameters used with their descriptions are collected in Tables 1 and 2 . The optimal values for the parameters were selected by the method of trials-and-errors. 


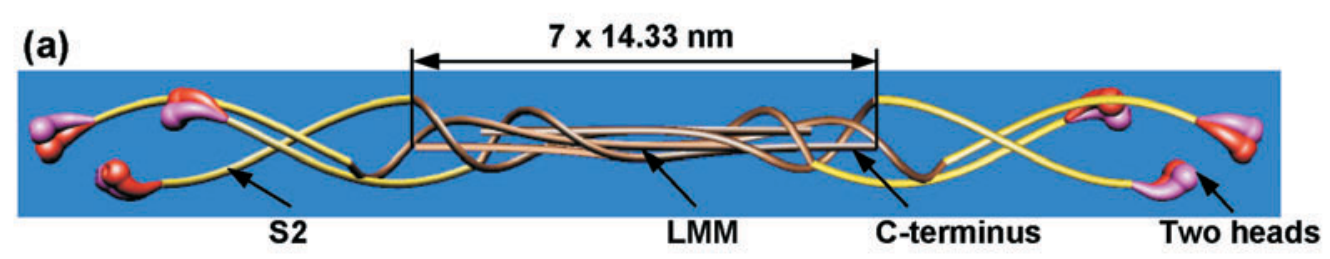

(b)

(c)

(d)

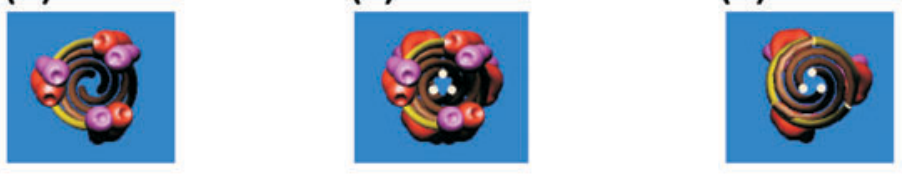

(e)

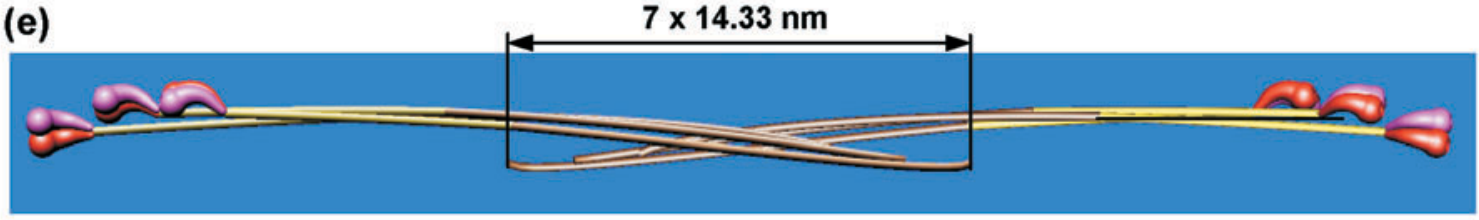

(f)

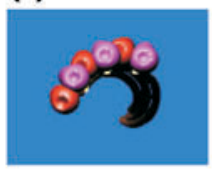

(g)

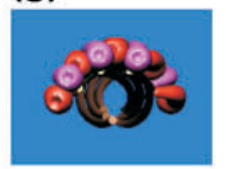

(h)

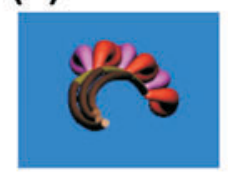

Figure 1. Scheme of the myosin molecules packing in the filament centre.

Only three successive crowns from each of the two polar halves are shown. Longitudinal views of the CB and TS models are shown in (a) and (e), respectively, and transverse views are in (b) and (f) for the left-hand halves, in (d) and (h) for the right-hand halves, and in (c) and (g) for the whole filament fragments.

$$
\begin{gathered}
x(t)=\left(r+t^{p}(R-r)\right) \cos \alpha t^{p} \\
y(t)=h t \\
z(t)=\left(r+t^{p}(R-r)\right) \sin \alpha t^{p} \\
t \in[0,1]
\end{gathered}
$$

$$
\begin{gathered}
x(t)=s \cos \beta t \\
y(t)=h t \\
z(t)=s \sin \beta t \\
t \in[0,1]
\end{gathered}
$$

Each myosin head (Fig. 2a) is constructed so as to obtain maximal similarity of its shape and dimensions to the original nucleotide-free structure (Rayment et al., 1993) (Fig. 2b). Because the three building units are connected into a continuous molecule the array of the heads on the filament surface is determined by positioning of the C-termini within the backbone (see Fig. 1). In the CB model, the trajectory for the arrangement of the 100.7-nm long LMM was selected such as to meet two essential demands: (1) to obtain the LMM projection on the filament axis $\mathrm{h}=86$ $\mathrm{nm}$ at correct values of the radii, $\mathrm{R}$ and $\mathrm{r}$, of the truncated cone along which the LMM is wrapped; (2) a 43-nm tail fragment from the C-terminus to be arranged near-parallel to the filament axis and the rest to be strongly twisted. Those were possible at $\alpha=360^{\circ}$ and $\mathrm{p}$ $=3$ (see Fig. 1a and Eqn. 1). In the case of the TS model, to obtain the filament backbone optimally similar to that modelled by Chew \& Squire (1995), i.e. the LMM to be straightened and tilted at about $3^{\circ}$ in relation to the filament axis, the parameter $p$ in Eqn. 1 was taken to be 0.5 . The parameter values for the S2 unit trajectory (Eqn. 2) were selected such 
Table 1. Comparison of the parameter values used for computation of both CB and TS models with the experimentally measured values

\begin{tabular}{|c|c|c|}
\hline & Model parameters & Experimental data and references \\
\hline Tail length & $162.7 \mathrm{~nm}^{*}$ & $\begin{array}{l}\text { 140-165 nm } \\
\text { (Lowey et al., 1969; Elliott \& Offer, 1978; Stew- } \\
\text { art \& Edwards, 1984) }\end{array}$ \\
\hline Tail diameter & $2 \mathrm{~nm}$ & $\begin{array}{l}2 \mathrm{~nm} \\
\text { (Lowey et al., 1969; Elliott \& Offer, 1978; Stew- } \\
\text { art \& Edwards, 1984) }\end{array}$ \\
\hline LMM length & $100.7 \mathrm{~nm}$ & $\begin{array}{l}75-100 \mathrm{~nm} \\
\text { (Lowey et al., 1969; Elliott \& Offer, 1978; Stew- } \\
\text { art \& Edwards, 1984) }\end{array}$ \\
\hline S2 length & $62.0 \mathrm{~nm}$ & $\begin{array}{l}62-77 \mathrm{~nm} \\
\text { (Lowey et al., 1969; Elliott \& Offer, 1978; Stew- } \\
\text { art \& Edwards, 1984) }\end{array}$ \\
\hline Length of the tail-hinge domain & $19 \mathrm{~nm}$ & $\begin{array}{l}19 \mathrm{~nm} \\
\text { (Stewart, 1984) }\end{array}$ \\
\hline $\begin{array}{l}\text { Diameter of the central, empty } \\
\text { core }(2 r)\end{array}$ & $4.6 \mathrm{~nm}$ & $\begin{array}{l}2-5 \mathrm{~nm} \\
\text { (Allakhverdov et al., 1981; Yu et al., 1985; Yu \& } \\
\text { Brenner, 1986) }\end{array}$ \\
\hline Diameter of the backbone ( $2 \mathrm{R})$ & $16.3 \mathrm{~nm}$ & $\begin{array}{l}\text { 10-18 nm } \\
\text { (Ip \& Heuser, 1983; Yu \& Brenner, 1986) }\end{array}$ \\
\hline $\begin{array}{l}\text { Diameter of the backbone when all } \\
\text { S2 lie on its surface }(2 \mathrm{~s})\end{array}$ & $\sim 20.3 \mathrm{~nm}$ & $\begin{array}{l}\text { 14-22 nm } \\
\text { (Kensler \& Stewart, 1983; Squire, 1992) }\end{array}$ \\
\hline $\begin{array}{l}\text { Diameter of the filament when all } \\
\text { heads lie on its surface }\end{array}$ & $\sim 28 \mathrm{~nm}$ & $\begin{array}{l}\text { 26-30 nm } \\
\text { (Ip \& Heuser, 1983; Cantino \& Squire, 1986) }\end{array}$ \\
\hline $\begin{array}{l}\text { Number of LMM visible in back- } \\
\text { bone cross-section }\end{array}$ & 18 & $\begin{array}{l}18 \\
\text { (Pepe, 1967) }\end{array}$ \\
\hline $\begin{array}{l}\text { Number of cross-bridges in a } \\
\text { crown }\end{array}$ & 3 & $\begin{array}{l}3 \\
\text { (Emes \& Rowe, 1978; Lamvik, 1978) }\end{array}$ \\
\hline $\begin{array}{l}\text { Axial translation between } \\
\text { cross-bridge crowns }\end{array}$ & $14.33 \mathrm{~nm}$ & $\begin{array}{l}14.3 \mathrm{~nm} \\
\text { (Huxley, 1963; Harrison et al., 1971) }\end{array}$ \\
\hline $\begin{array}{l}\text { Axial translation between helical } \\
\text { stripes }\end{array}$ & $43 \mathrm{~nm}$ & $\begin{array}{l}43 \mathrm{~nm} \\
\text { (Huxley, 1963; Harrison et al., 1971) }\end{array}$ \\
\hline
\end{tabular}

*The length of the whole tail is taken as a multiple of the $0.1485 \mathrm{~nm} /$ residue factor, evaluated by Fraser (Fraser \& MacRae, 1973) for a coiled-coil $\alpha$-helix, and average number of amino-acid residues in myosin tails (1101 residues for rat (Strehler $e t$ al., 1986), 1098 for rabbit (Elzinga \& Trus, 1980) and 1092 for chicken (Molina et al., 1987)).

as to obtain good consistency with the experimental dimensions for the S2 length, the filament thickness, and the lengths of both the whole filament and the bare zone at a correct number of both molecules and cross-bridge crowns. Because the values of all of the mentioned parameters are well contained in the experimentally proven ranges (see Table 1) the same parameter values were also incorporated into the TS model. The same parameter values were also used for creation of the myosin head (see Fig. 2).

For creation of the bipolar structure of the filaments a scheme for mutual arrangement of the myosin tails is explored as follows (see Fig. 1). (1) The maximal overlapping between the oppositely oriented tails in the filament centre is taken to be $7 \times 14.33 \mathrm{~nm}$. (2) The successive tails in each filament half, and therefore the related crowns, are axially stag- 
Table 2. Parameter values which differ CB model from TS model

\begin{tabular}{|c|c|c|}
\hline & CB model & TS model and references \\
\hline Cross-bridge alignment in a crown & $0^{\circ} / 120^{\circ} / 180^{\circ}$ & $\begin{array}{l}0^{\circ} / 120^{\circ} / 240^{\circ} \\
\text { (Squire, 1973; Kensler \& Stewart, 1983; } \\
\text { Hudson et al., 1997; Eakins } \text { et al., 2002) }\end{array}$ \\
\hline $\begin{array}{l}\text { Angle of LMM rotation around fila- } \\
\text { ment axis }(\alpha)\end{array}$ & $360^{\circ}$ & $\begin{array}{l}120^{\circ} \\
\text { (Chew \& Squire, 1995) }\end{array}$ \\
\hline $\begin{array}{l}\text { Angle of } \mathrm{S} 2 \text { rotation around filament } \\
\text { axis }(\beta)\end{array}$ & $180^{\circ}$ & $\begin{array}{l}30^{\circ} \\
\text { (Chew \& Squire, 1995) }\end{array}$ \\
\hline Value of parameter $p$ in Equation 1 & 3 & 0.5 \\
\hline Rotation between successive crowns & $240^{\circ}$ & $\begin{array}{l}40^{\circ} \\
\text { (Squire, 1973; Luther \& Squire, 1980) }\end{array}$ \\
\hline Rotation between two polar halves & $120^{\circ}$ & $\begin{array}{l}40^{\circ} \\
\text { (Luther \& Squire, 1980) }\end{array}$ \\
\hline Alignment of two heads relative to $\mathrm{S} 2$ & $\begin{array}{l}\gamma_{1}=10^{\circ} ; \varphi_{1}=25^{\circ} ; \\
\gamma_{2}=-10^{\circ} ; \varphi_{2}=25^{\circ}\end{array}$ & $\begin{array}{l}\gamma_{1}=10^{\circ} ; \varphi_{1}=45^{\circ} \\
\gamma_{2}=-10^{\circ} ; \varphi_{2}=40^{\circ}\end{array}$ \\
\hline
\end{tabular}

gered by $14.33 \mathrm{~nm}$. (3) Each of the three successive crowns located both adjacently to the bare zone and at the ends of the filament consists of one cross-bridge; the remaining crowns contain three cross-bridges.

The parameter values collected in Table 2 demonstrate the main differences introduced for the creation of the two models.

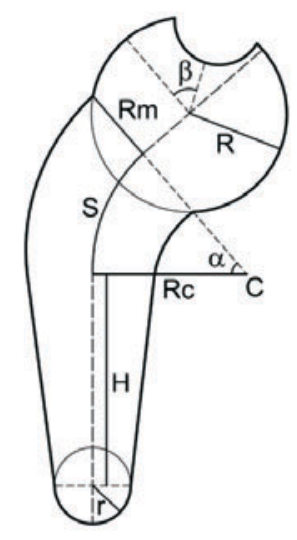

(a)

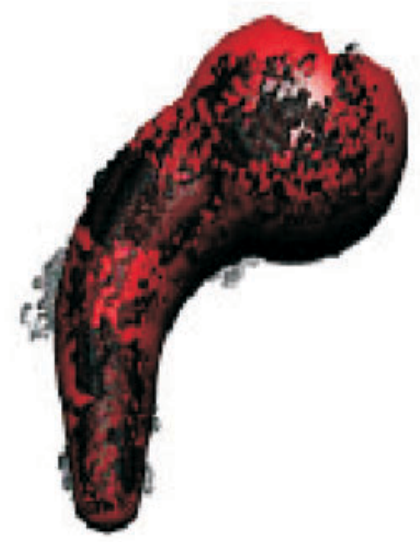

(b) probable than that proposed so far. It is first of all because the twisted myosin tails (see Fig. 1a and Table 2) do ensure modelling of the complete bipolar structure (CB model, Fig. 3) with features well consistent with those experimentally observed (Sjöström \& Squire, 1977; Ip \& Heuser, 1983; Kensler \& Stewart, 1983; Cantino \& Squire, 1986;

Figure 2. Myosin head.

(a) The parameter values used: $\mathrm{R}=6.4 \mathrm{~nm} ; \mathrm{r}=2 \mathrm{~nm} ; \mathrm{H}=$ $3.5 \mathrm{~nm} ; \alpha=69^{\circ} ; \beta=52^{\circ} ; \mathrm{L}=16.5 \mathrm{~nm} ; \mathrm{R}_{\mathrm{m}}=4.57 \mathrm{~nm} ; \mathrm{R}_{\mathrm{c}}=$ $5.66 \mathrm{~nm}$. (b) Superposing of the head model devised by Rayment (1993) (black) on our model (red). The hollow depicts the specific actin-binding interface.

Kensler \& Stewart, 1986; Stewart \& Kensler, 1986; Kensler et al., 1994; Kensler \& Woodhead, 1995; Levine, 1997; Cantino et al., 2002; Eakins et al., 2002). The unique consistency relates not only to the filament appear-

ance (compare Figs. 3 and $4 \mathrm{a}$ with the fila-
The approach used for the computer modelling has revealed that the new mode for the myosin molecule packing within the thick filaments of vertebrate skeletal muscles is more 


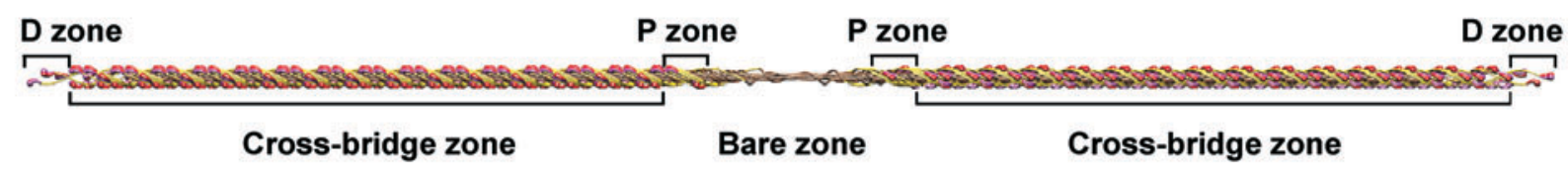

Figure 3. Complete bipolar structure of the vertebrate skeletal muscle thick filament (CB model).

The model reveals four zones characteristic for the vertebrate skeletal muscle thick filaments (Sjöström \& Squire, 1977). In both cross-bridge zones there are identically tilted stripes consisting of the head pairs. The central bare zone is devoid of the heads. In the P- and D-zones, two of the three cross-bridge crowns are visible.

ment description in the Introduction) but also to the dimensions of both the whole filament and the myosin subfragments (see Tables 1 and 3).

Different numbers of cross-bridges in the crowns localized in the cross-bridge zone (three) and in the P- and D-zones (one) introduced for creation of both models (compare Figs. 1 and 4) have allowed modelling the tation $240^{\circ}$ between successive crowns, introduced into the $\mathrm{CB}$ model, has ensured the characteristic profile looking as an equilateral triangle in a transverse view of the filament (Luther \& Squire, 1980; Craig et al., 1992); the rotation $40^{\circ}$ incorporated into the TS model precludes such profiles (compare Figs. $1 \mathrm{~b}$ and $1 \mathrm{~d}$ with $1 \mathrm{f}$ and $1 \mathrm{~h}$ ). Furthermore, the rotation $120^{\circ}$ between the two filament halves, intro-

(a)
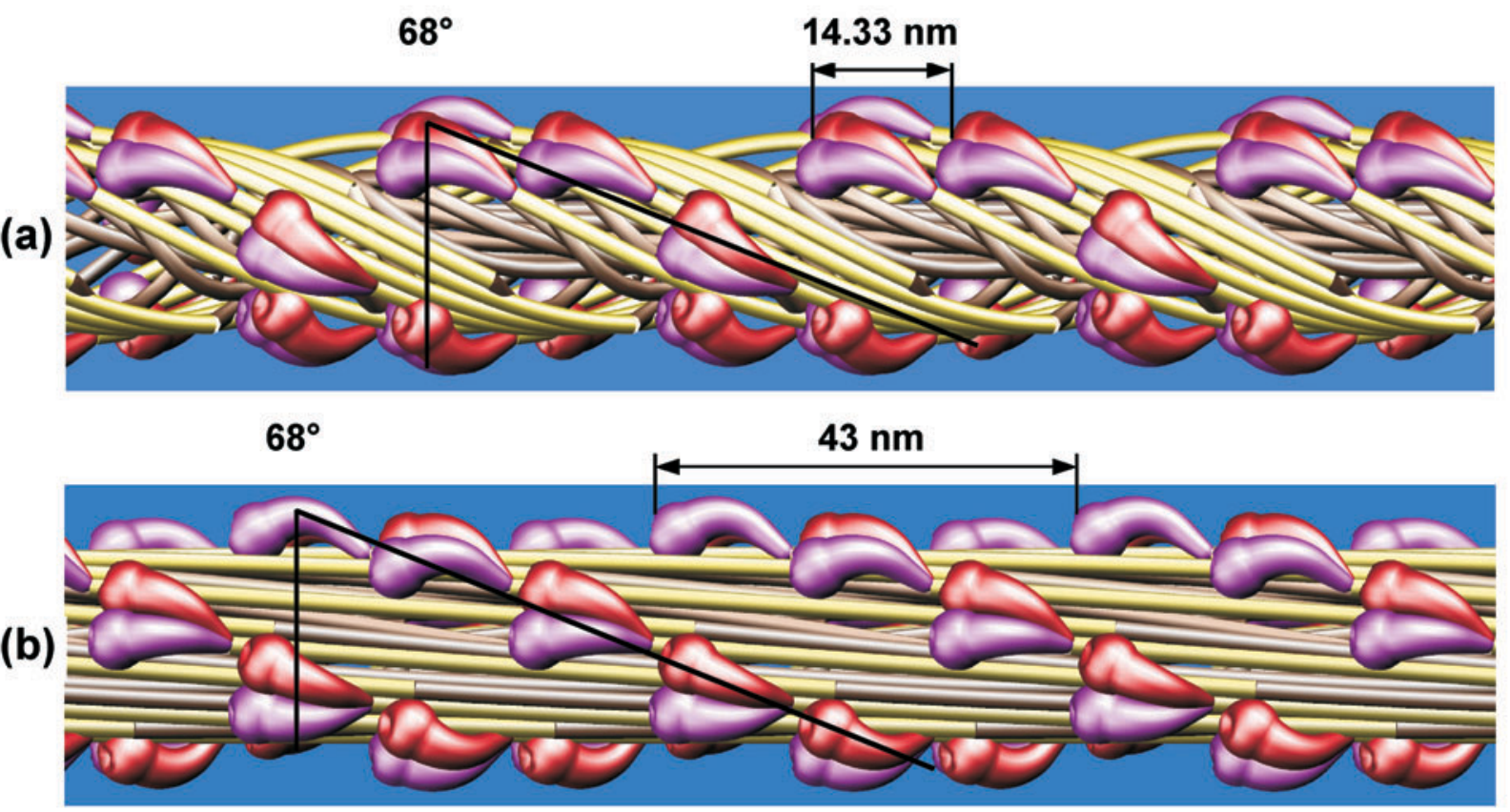

Figure 4. Cross-bridge zone fragments of CB model (a) and TS model (b).

In the CB model, the inclined stripes and the gaps between them are more prominent than in the TS model. Along each stripe there are 4 or 5 pairs of heads in the CB model and 6 or 7 in the TS model, although inclination of the stripes, $68^{\circ}$ in relation to the normal, and axial translations, $14.33 \mathrm{~nm}$ between the crowns and $43 \mathrm{~nm}$ between the stripes, are the same.

characteristic zoning of the thick filament (Sjöström \& Squire, 1977; Luther \& Squire, 1980; Craig et al., 1992). However, only the ro- duced into the CB model instead of the rotation $40^{\circ}$ suggested by Squire and co-workers (Squire, 1973; Luther \& Squire, 1980) and in- 
corporated into the TS model, has brought about a $60^{\circ}$ rotation between the triangles depicting the filament transverse profiles from the two halves (compare Figs. 1c and 1g) consistent with that experimentally observed (Luther \& Squire, 1980).
(1977). The bare-zone length, found in the literature, is contained in a fairly wide range, from $130 \mathrm{~nm}$ to $200 \mathrm{~nm}$ (Morimoto \& Harrington, 1973; Craig, 1977; Sjöström \& Squire, 1977; Trinick \& Elliott, 1979; Cantino et al., 2002) probably because it was measured for

Table 3. Comparison between dimensions computed for CB model and measured experimentally for thick filaments

\begin{tabular}{|c|c|c|}
\hline & CB model & Experimental data and references \\
\hline Filament length & $1575.68 \mathrm{~nm}$ & $\begin{array}{l}1560-1630 \mathrm{~nm} \\
\text { (Morimoto \& Harrington, 1973; Craig, 1977; Trinick \& } \\
\text { Elliott, 1979; Cantino et al., 2002) }\end{array}$ \\
\hline $\begin{array}{l}\text { Bare-zone length in the relaxed } \\
\text { state }\end{array}$ & $200 \mathrm{~nm}$ & $\begin{array}{l}\text { 130-200 nm } \\
\text { (Morimoto \& Harrington, 1973; Craig, 1977; Sjöström }\end{array}$ \\
\hline and in the rigor state & $150 \mathrm{~nm}$ & $\begin{array}{l}\text { \& Squire, 1977; Trinick \& Elliott, 1979; Cantino et al., } \\
\text { 2002) }\end{array}$ \\
\hline P-zone length & $43 \mathrm{~nm}$ & $\begin{array}{l}43 \mathrm{~nm} \\
\text { (Sjöström \& Squire, 1977) }\end{array}$ \\
\hline D-zone length & $43 \mathrm{~nm}$ & $\begin{array}{l}43 \mathrm{~nm} \\
\text { (Sjöström \& Squire, 1977) }\end{array}$ \\
\hline $\begin{array}{l}\text { Number of myosin molecules in the } \\
\text { whole filament }\end{array}$ & 288 & $\begin{array}{l}200-400 \\
\text { (Tregear \& Squire, 1973; Pepe \& Drucker, 1979) }\end{array}$ \\
\hline Number of cross-bridge crowns & 98 & $\begin{array}{l}98 \\
\text { (Craig, 1977) }\end{array}$ \\
\hline $\begin{array}{l}\text { Number of cross-bridges visible } \\
\text { around the filament backbone in } \\
\text { transverse view }\end{array}$ & 6 & $\stackrel{6}{\text { (Yu \& Brenner, 1986; Craig et al., 1992) }}$ \\
\hline
\end{tabular}

It is also worth noting that the quite strong degree of twisting, introduced into the CB model instead of the weak one incorporated into the TS model (see Table 2), gives rise to the length of the whole filament equal to that recently measured by Cantino et al. (2002) at a correct number of both the myosin molecules and the cross-bridge crowns (see Table 3). This is impossible in the case of the TS model because of the straightened configuration of the tails. Furthermore, the bare-zone length, which we evaluated at about $200 \mathrm{~nm}$ for the CB model in relaxed state, agrees well with the distance between the P2 peaks measured by Cantino et al. (2002). During muscle contraction, the bare-zone length should decrease because of the cross-bridge unwrapping. We have estimated it as being $150 \mathrm{~nm}$ long; this value agrees with that measured by Craig different muscle conditions. Moreover, previously the bare-zone length was identified with the distance between the M9 peaks, but according to the recent conclusion made by Cantino et al. (2002) it should be related either to the P1 peak or to P2. The foregoing results are impossible to obtain at the near-parallel arrangement of the myosin tails, incorporated into the TS model (see Figs. 1e and 4b).

The appearance of the filament cross-bridge zone is determined not only by the crossbridge crown configuration but also by the manner of the myosin tail arrangement. At the same degree of the tail twisting (Skubiszak, 1996b) it was difficult to make a decisive selection between symmetrical and asymmetrical configurations of the crossbridge crowns. At different degrees of twisting (see Figs. 1 and 4), the appearances of the 
cross-bridge zones are markedly different. In the CB model, the inclined stripes formed by the myosin heads are identical with those observed experimentally (Sjöström \& Squire, 1977; Ip \& Heuser, 1983; Cantino \& Squire, 1986; Kensler \& Stewart, 1986; Kensler et al., 1994; Kensler \& Woodhead, 1995; Levine, 1997; Eakins et al., 2002). In the TS model, the helical stripes are too long and narrow. Better consistency could be also obtained for the TS model but only after introduction of some perturbations in the arrangement of the myosin heads (data not shown), for instance, by introduction of different diameters of three successive crowns, as suggested by Stewart and Kensler (1986), or by mutual shifting of the two heads, as suggested by Hudson et al. (1997). However, no perturbation can overcome the consequences of the symmetrical cross-bridge crown configuration.

The cross-bridge crown configuration has direct influence on the filament symmetry and on the number of the cross-bridges protruding

\section{(a)}

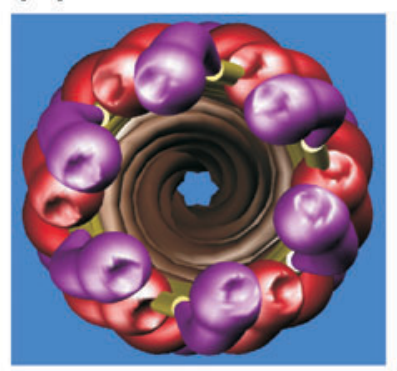

(b)

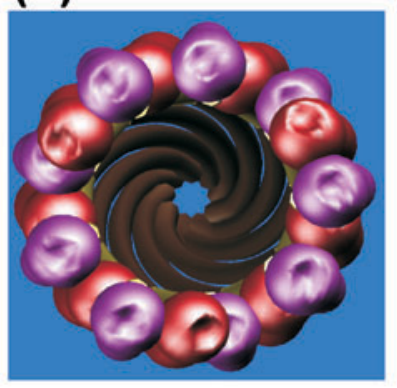

from the filament backbone. In these terms, the two models, CB and TS, differ essentially. The question of the symmetries is widely discussed in accompanying paper (Skubiszak \& Kowalczyk, 2002). The latter relation is demonstrated in Fig. 5: the configuration with asymmetrical alignment of the three cross-bridges in a crown (Fig. 5c, CB model) gives rise to correct relation between the protruding cross-bridges and surrounding thin filaments, there are six to six; at the configuration with symmetrical crowns (Fig. 5d, TS model), there are nine to six.

\section{CONCLUSIONS}

Concurrent modelling of the whole, bipolar structure of the vertebrate skeletal muscle thick filament on the basis of two alternative modes to a scale of all dimensions has provided a number of new arguments for the reality of the concept proposed by us on the myo-

(c)

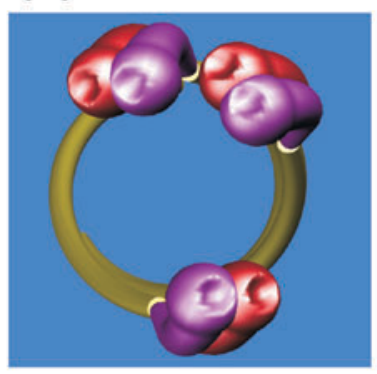

(d)

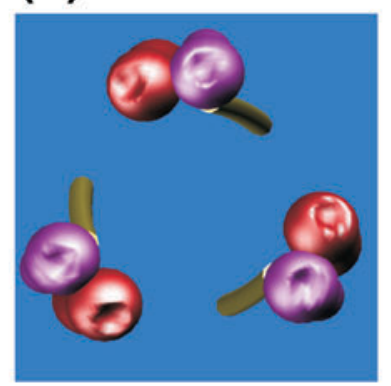

Figure 5. Transverse views of CB model (upper row) and TS model (lower row). Both models have a tube-like backbone covered by a coat of heads.

There are 6 and 9 pairs of heads in the CB model (a) and the TS model (b), respectively. The tube wall is sufficiently massive in comparison with the empty centre. (c) and (d), arrangement of three cross-bridges, i.e. three pairs of heads tethered by $\mathrm{S} 2$, into asymmetrical and symmetrical crowns, respectively. 
sin molecule packing. It is worth emphasizing that only the configurations both twisted for the myosin tails and asymmetrical for the cross-bridge crowns allow creation of the filament appearance consistent with that observed by EM in both transverse (compare Fig. 5a with that presented in Allakhverdov et al., 1981; Yu et al., 1985; Yu \& Brenner, 1986) and longitudinal views (compare Fig. 3 with that presented in Sjöström \& Squire, 1977; Ip \& Heuser, 1983; Kensler \& Stewart, 1983; Cantino \& Squire, 1986; Kensler \& Stewart, 1986; Stewart \& Kensler, 1986; Kensler et al., 1994; Kensler \& Woodhead, 1995; Levine, 1997; Cantino et al., 2002; Eakins et al., 2002).

The myosin molecule packing by twisting seems to be reasonable for all thick filaments. So far, we have used it for modelling of the vertebrate and tarantula thick filaments. The data related to the tarantula thick filament would be published elsewhere.

Unfortunately, none of the presently available experimental methods could confirm in a direct way the manner of packing of the myosin molecules. Verification of the two alternative modes by such experimental methods as $\mathrm{EM}$ and diffraction is presented in the accompanying paper (Skubiszak \& Kowalczyk, 2002).

\section{R E F E R E N C E S}

Allakhverdov BL, Shpagina MD, Podlubnaya ZA. (1981) Study on structural elements of sarcomere: structure of thick filaments in muscle and after isolation. Acta Histochem.; 23: 83-7.

Burke M, Harrington W. (1972) Geometry of the myosin dimer in high-salt media. II. Hydrodynamic studies on macromodels of myosin and its rod segments. Biochemistry.; 11: 1456-62.

Cantino M, Squire JM. (1986) Resting myosin cross-bridge configuration in frog muscle thick filaments. J Cell Biol.; 102: 610-8.

Cantino ME, Brown LD, Chew M, Luther PK, Squire JM. (2000) A-band architecture in ver- tebrate skeletal muscle: polarity of the myosin head array. J Muscle Res Cell Motil.; 21: 681-90.

Cantino ME, Chew MW, Luther PK, Morris E, Squire JM. (2002) Structure and nucleotide-dependent changes of thick filaments in relaxed and rigor plaice fin muscle. $J$ Struct Biol.; 137: 164-75.

Chew MWK, Squire JM. (1995) Packing of $\alpha$-helical coiled-coil myosin rods in vertebrate muscle thick filaments. J Struct Biol.; 115: 223-49.

Cohen C, Holmes KC. (1963) X-ray diffraction evidence for $\alpha$-helical coiled-coils in native muscle. J Mol Biol.; 6: 423-32.

Craig R. (1977) Structure of A-segments from frog and rabbit skeletal muscle. $J \mathrm{Mol} \mathrm{Biol}$; 109: $69-81$.

Craig R, Alamo L, Padron R. (1992) Structure of the myosin filaments of relaxed and rigor vertebrate striated muscle studied by rapid freezing electron microscopy. J Mol Biol.; 228: $474-87$.

Eakins F, AL-Khayat HA, Kensler RW, Morris EP, Squire JM. (2002) 3D structure of fish muscle myosin filaments. J Struct Biol.; 137: 154-63.

Elliott A, Offer G. (1978) Shape and flexibility of the myosin molecule. $J$ Mol Biol.; 123: $505-19$.

Elzinga M, Trus B. (1980) Methods in peptide and protein sequence analysis. Elsevier/ North-Holland, New York.

Emes CH, Rowe A. (1978) Frictional properties and molecular weight of native and synthetic myosin filaments from vertebrate skeletal muscle. Biochim Biophys Acta.; 537: 125-44.

Fraser RDB, MacRae TP. (1973) Conformation in fibrous proteins. Academic Press, New York.

Geeves MA, Holmes KC. (1999) Structural mechanism of muscle contraction. Annu Rev Biochem.; 68: 687-728.

Harrison RG, Lowey S, Cohen C. (1971) Assembly of myosin. J Mol Biol.; 59: 531-5. 
Hudson L, Harford JJ, Denny RC, Squire JM. (1997) Myosin head configuration in relaxed fish muscle: resting state myosin heads must swing axially by up to $150 \AA$ or turn upside down to reach rigor. $J$ Mol Biol.; 273: 440-55.

Huxley AF. (1980) Reflection on muscle. Princeton, Princeton University Press, New Jersey.

Huxley HE. (1963) Electron microscope studies on the structure of natural and synthetic protein filaments from striated muscle. $\mathrm{J} \mathrm{Mol}$ Biol.; 7: 281-308.

Ip W, Heuser J. (1983) Direct visualization of the myosin cross-bridge helices on relaxed rabbit psoas thick filaments. $J$ Mol Biol.; 171: $105-9$.

Kensler RW, Stewart M. (1983) Frog skeletal muscle thick filaments are three-stranded. $J$ Cell Biol.; 96: 1797-802.

Kensler RW, Stewart M. (1986) An ultrastructural study of cross-bridge arrangement in the frog thigh muscle thick filament. Biophys J.; 49: 343-51.

Kensler RW, Woodhead JL. (1995) The chicken muscle thick filament: temperature and the relaxed cross-bridge arrangement. $J$ Muscle Res Cell Motil.; 16: 79-90.

Kensler RW, Peterson S, Norberg M. (1994) The effects of changes in temperature or ionic strength on isolated rabbit and fish skeletal muscle thick filaments. J Muscle Res Cell Motil.; 15: 69-79.

Lamvik MK. (1978) Muscle thick filament mass measured by electron scattering. J Mol Biol.; 122: $55-68$.

Levine RJC. (1997) Differences in myosin head arrangement of relaxed thick filaments from Lethocerus and rabbit muscles. J Muscle Res Cell Motil.; 18: 529-43.

Lowey S, Slayter H, Weeds A, Baker H. (1969) Substructure of the myosin molecule. 1. Subfragments of myosin by enzymic degradation. J Mol Biol.; 42: 1-29.

Luther PK, Squire JM. (1980)

Three-dimensional structure of the vertebrate muscle A-band. II. The myosin filament superlattice. J Mol Biol.; 141: 409-39.

Molina MI, Kropp KE, Gulick J, Robbins J. (1987) The sequence of an embryonic myosin heavy chain gene and isolation of its corresponding cDNA. J Biol Chem.; 262: 6478-88.

Morimoto K, Harrington WF. (1973) Isolation and composition of thick filaments from rabbit skeletal muscle. J Mol Biol.; 77: 165-75.

Offer G. (1990) Skip residues correlate with bends in the myosin tail. $J$ Mol Biol.; 216: 213-8.

Pepe FA. (1967) The myosin filament. 1. Structural organization from antibody staining observed in electron microscopy. J Mol Biol.; 27: 203-25.

Pepe FA, Drucker B. (1979) The myosin filament. 6. Myosin content. J Mol Biol.; 130: 379-93.

Rayment I, Rypniewski WR, Schmidt-Bäse K, Smith R, Tomchick DR, Benning MM, Winkelmann DA, Wessenberg G, Holden HM. (1993) Three-dimensional structure of myosin subfragment-1: a molecular motor. Science.; 261: $50-8$.

Sjöström M, Squire JM. (1977) Fine structure of the A-band in cryo-sections. J Mol Biol.; 109: $49-68$.

Skubiszak L. (1990) Molecular organization in thick filament. Cell Biol.; 14: 207.

Skubiszak L. (1992) New conception on muscle contraction mechanism: 1. Structural matching between the thick and thin filaments. $J$ Muscle Res Cell Motil.; 13: 254.

Skubiszak L. (1993) Force generation in muscle: 1. Molecular organization in the thick filament. Biocyb Biomed Eng.; 13: 75-96.

Skubiszak L. (1996a) Structure and functional significance of the thick filament. Biophysics.; 41: 39-56.

Skubiszak L. (1996b) Arrangement of myosin crossbridges on the surface of vertebrate skeletal muscle thick filament. Biophysics.; 41: $1167-74$. 
Skubiszak L, Kowalczyk L. (1998). Computer system modelling muscle work. Technol Health Care.; 6: 139-49.

Skubiszak L, Kowalczyk L. (2001) Relation between the mechanical properties of muscles and their structure on the molecular level. Engineering Transactions.; 49: 191-212.

Skubiszak L, Kowalczyk L. (2002) The vertebrate skeletal muscle thick filaments are not three-stranded. Reinterpretation of some experimental data. Acta Biochim Polon.; 49: 841-853.

Squire JM. (1972) General model of myosin filament structure. 2. Myosin filaments and crossbridge interactions in vertebrate striated and insect flight muscles. $J$ Mol Biol.; 72: $125-38$.

Squire JM. (1973) General models of myosin filament structure. 3. Molecular packing arrangements in myosin filaments. $J$ Mol Biol.; 77: 291-323.

Squire JM. (1981) The structural basis of muscular contraction. Plenum Press, New York.

Squire JM. (1992) Muscle filament lattice and stretch-activation: the match-mismatch model reassessed. J Muscle Res Cell Motil.; 13: 183-9.

Squire JM. (1997) Architecture and function in the muscle sarcomere. Curr Opin Struct Biol.; 7: 247-57.
Stewart M, Edwards P. (1984) Length of myosin rod and its proteolytic fragments determined by electron microscopy. FEBS Lett.; 168: $75-8$.

Stewart M, Kensler R. (1986) Arrangement of myosin heads in relaxed thick filaments from frog skeletal muscle. J Mol Biol.; 192: 831-51.

Strehler EE, Strehler-Page MA, Perriard JC, Periasamy M, Nadal-Ginard B. (1986) Complete nucleotide and encoded amino acid sequence of a mammalian myosin heavy chain gene. Evidence against intron-dependent evolution of the rod. J Mol Biol.; 190: 291-317.

Tregear RT, Squire JM. (1973) Myosin content and filament structure in smooth and striated muscles. J Mol Biol.; 77: 279-90.

Trinick J, Elliott A. (1979) Electron microscope studies of thick filaments from vertebrate skeletal muscle. J Mol Biol.; 131: 133-6.

Yu LC, Brenner B. (1986) High-resolution equatorial X-ray diffraction from single skinned rabbit psoas fibers. Biophys J.; 49: 133-5.

Yu LC, Steven AC, Naylor GR, Gamble RC, Podolsky RJ. (1985) Distribution of mass in relaxed frog skeletal muscle and its redistribution upon activation. Biophys J.; 47: 311-21. 